\title{
THE TONIC PUPIL
}

\author{
BY \\ G. S. GRAVESON \\ From the Department of Neurology, Manchester Royal Infirmary
}

The peculiar phenomenon of the tonic pupil was first described in detail by Strasburger in 1902. Later in the same year both Saenger and Nonne reported further cases and Saenger proposed the name "myotonic pupillary movement" for the condition. Until this time the disorder had not been separated from others causing mydriasis or alteration in the pupillary reflexes. Yet the curious slowness of pupillary movement, characteristic of the condition, must have been recognized earlier ; indeed in 1818 James Ware described a patient who very probably had a tonic pupil. His patient, whose pupillary abnormality had been known to exist for at least twenty years, was " a lady between twenty and thirty years of age, the pupil of whose right eye, when she is not engaged in reading or in working with her needle, is always dilated very nearly to the rim of the cornea ; but whenever she looks at a small object, nine inches from the eye, it contracts within less than a minute to a size nearly as small as the head of a pin ... its contraction never remains long after the attention is withdrawn from a near object."

After 1902 the condition was reported on several occasions, both in this country (Markus, 1906 ; Weber, 1923 ; Moore, 1923, 1931 ; and Morgan and Symonds 1927, 1931) and abroad, but it did not attract much attention until the work of Holmes (1931) and Adie $(1931,1932)$. To Adie in particular must be given the credit for attempting a synthesis of available information into a semeiological plan. He divided the tonic pupil into two forms, the typical and the atypical, each of which might be associated with absence of one or more tendon reflexes, but with no other neurological abnormality. Collier (1933) first called this combination "Adie's Syndrome," a name which has been generally applied in Europe and America. In this country, following Bramwell's (1936) suggestion, the double eponymous title of the "Holmes-Adie syndrome" has been perhaps more widely used.

The "typical" tonic pupil, in Adie's view, was a unilateral disorder in which the affected pupil was larger than normal, did not react to torch light but dilated slowly in the dark, subsequently contracting slowly in daylight, and showed a characteristically slow contraction and relaxation with ocular convergence. The "atypical" forms were less clearly defined but included some forms of internal ophthalmoplegia and complete light rigidity with a tonic convergence reaction. Since Adie's description, this conception of the atypical tonic pupil has been so far enlarged upon that, for example, Lowenstein and Friedman (1942) write, "In atypical cases all the modifications observable in pupillary disease both of syphilitic and other causation may be exhibited." Similarly Alajouanine and Morax (1938) claim that between the typical tonic pupil and the Argyll Robertson pupil all intermediary forms are possible. If these statements are even partly true the practical difficulties of diagnosis which not infrequently arise are understandable enough.

Apart from what distinctive pupillary abnormalities must necessarily be found before a diagnosis can be made, two other problems remain to be solved: (1) the site of the anatomical lesion and (2) the nature and specificity, or otherwise, of the underlying pathological process. This paper is an attempt to throw light on some of these problems.

\section{Clinical Observations}

Fifteen patients, twelve females and three males, varying in age from 12 to 55 years, have been studied, in each of whom was found evidence of "tonicity" of one or more of the three principal actions of the intrinsic ocular muscles, viz : pupillary contraction on exposure to light and. with ocular convergence, and the ciliary muscle response to accommodation. The detailed clinical findings in these patients are set out in Tables I and II.

Symptoms.-Of the fifteen patients, eleven were originally seen because of pupillary inequality noticed either by themselves, their friends, or their doctors; and four attended because of blurring of vision with or without headaches. 


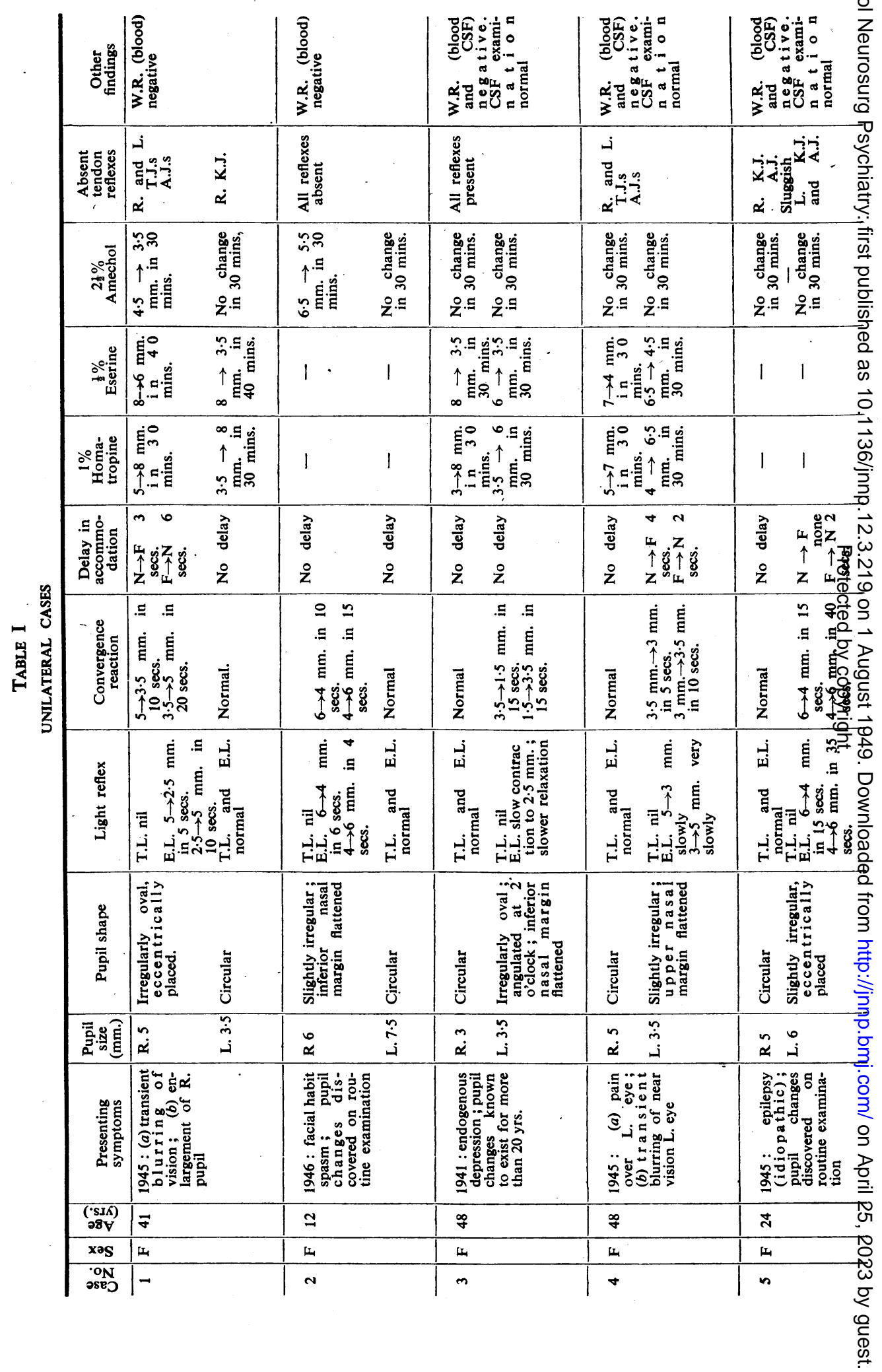




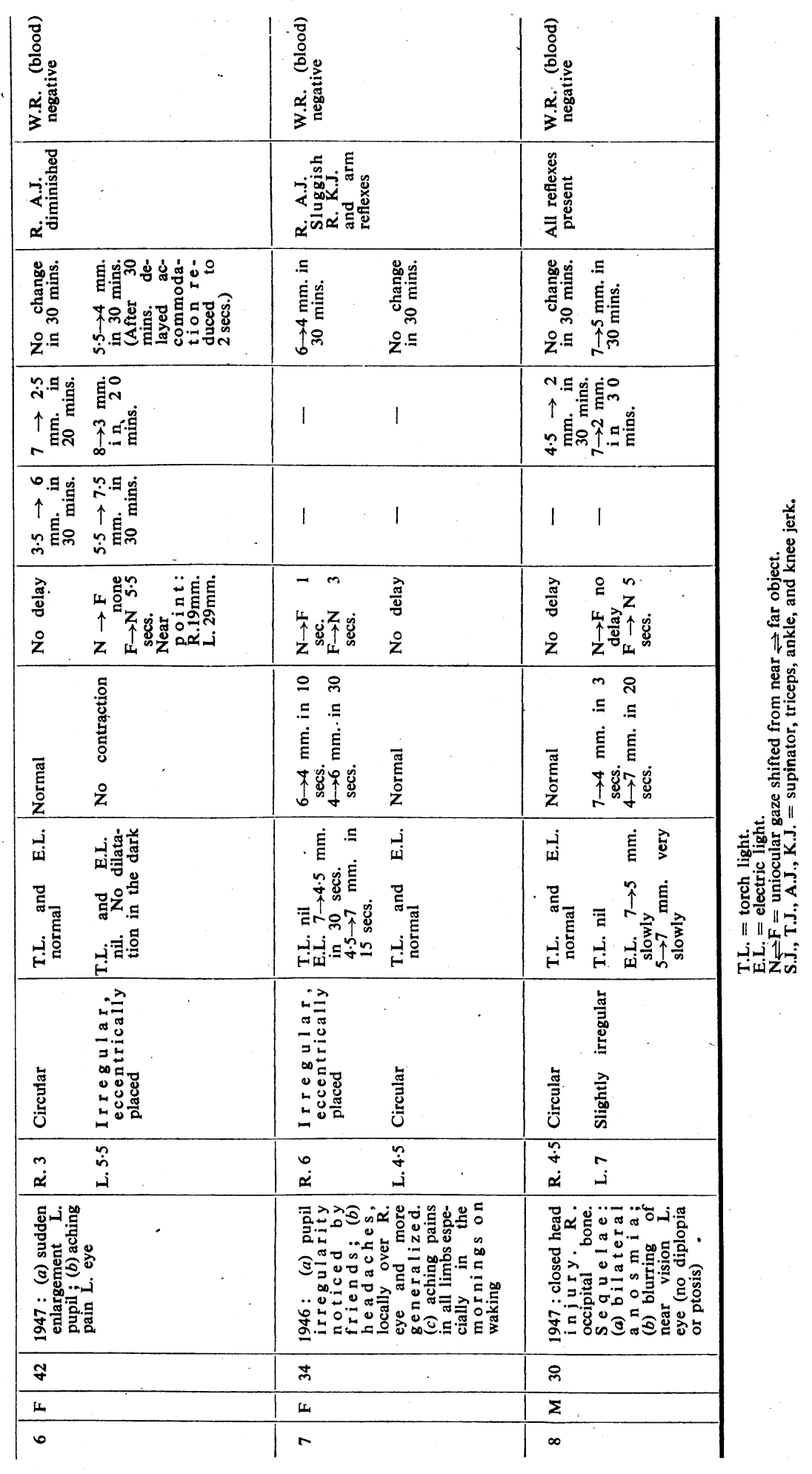

221 


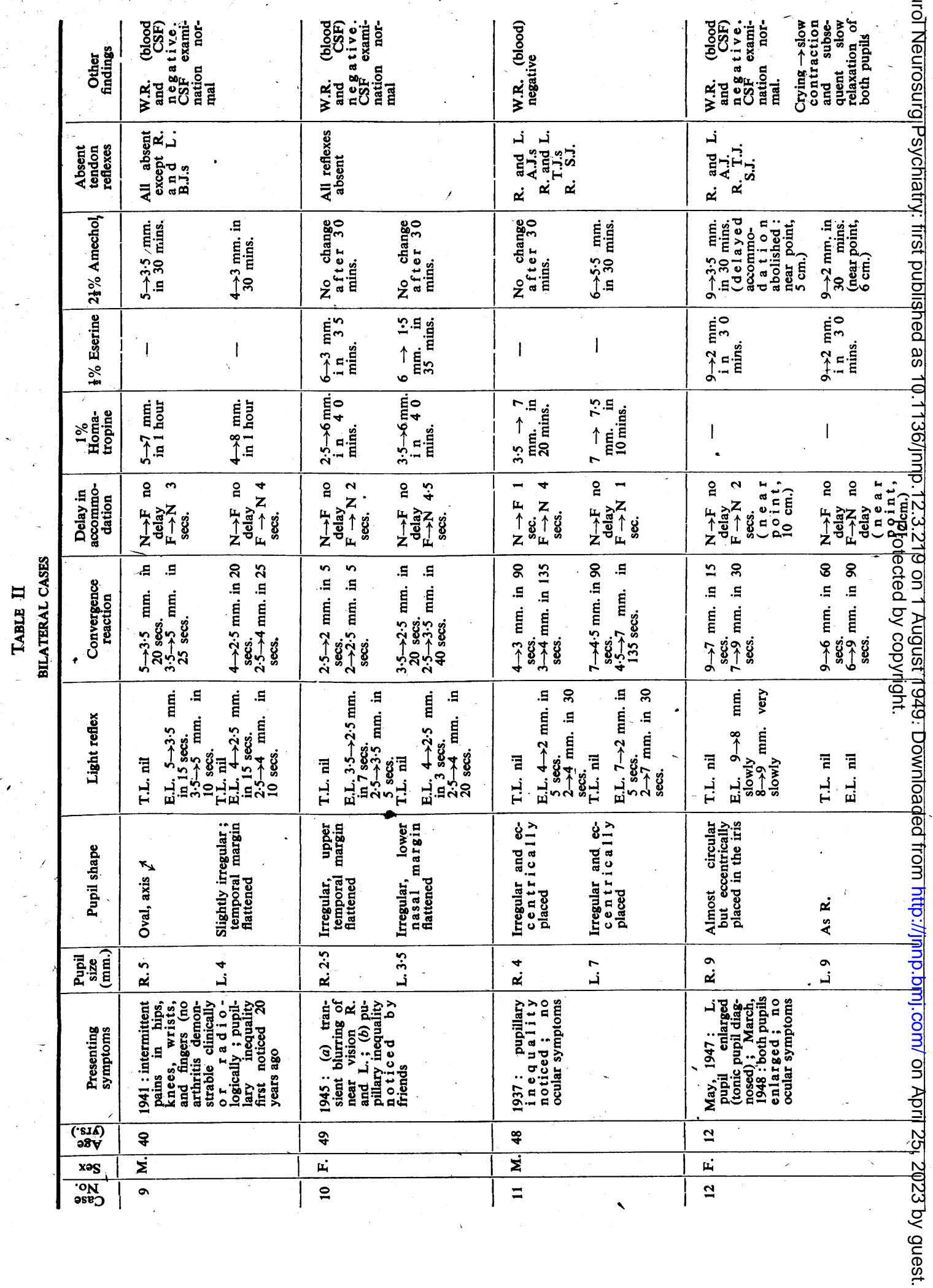




\begin{tabular}{|c|c|c|}
\hline 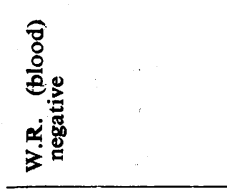 & 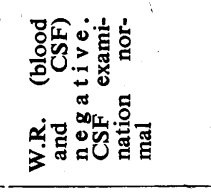 & 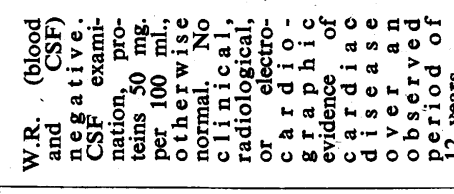 \\
\hline 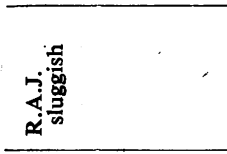 & 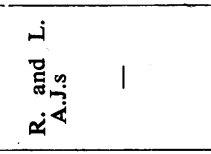 & 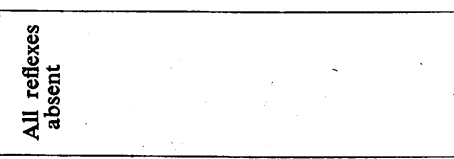 \\
\hline 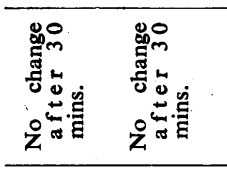 & 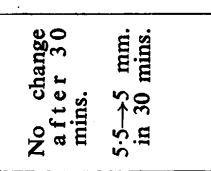 & 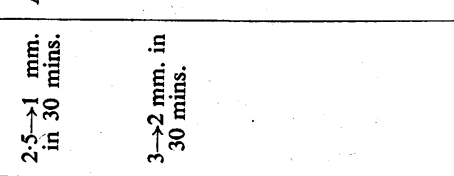 \\
\hline 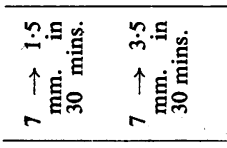 & 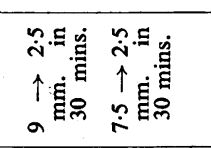 & $11-$ \\
\hline 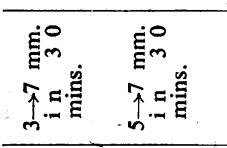 & 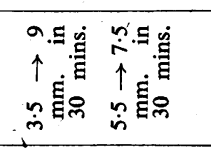 & 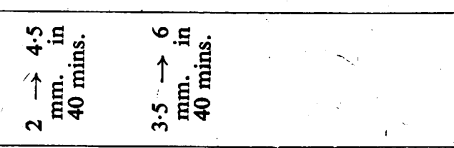 \\
\hline 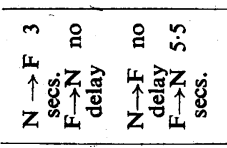 & 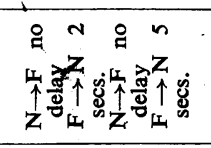 & 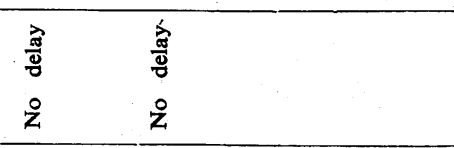 \\
\hline 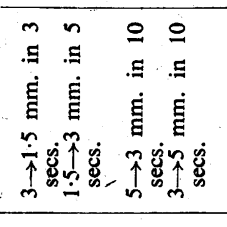 & 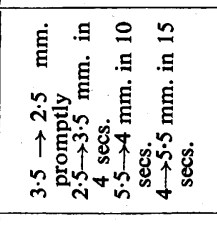 & 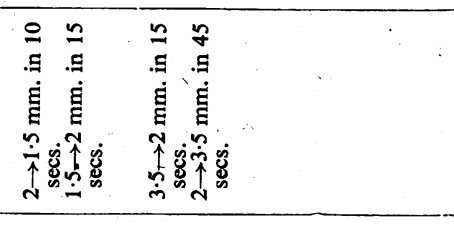 \\
\hline 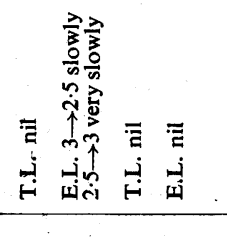 & 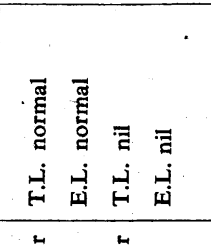 & 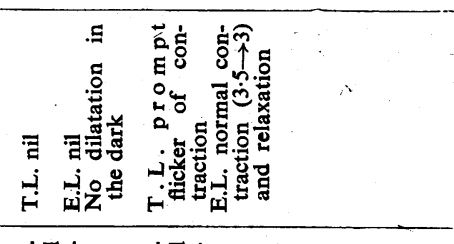 \\
\hline 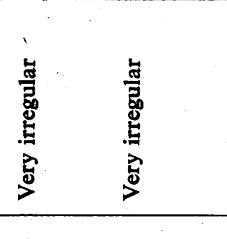 & 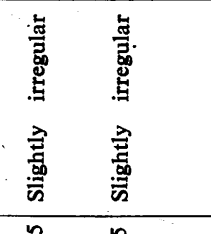 & 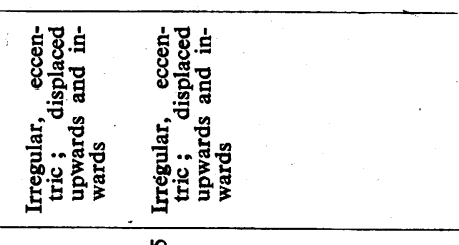 \\
\hline 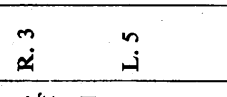 & 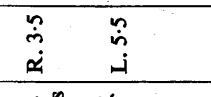 & $\dddot{\varkappa} \quad \stackrel{n}{i}$ \\
\hline 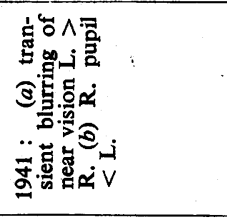 & 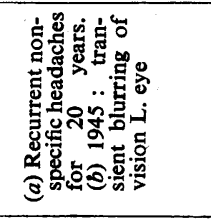 & 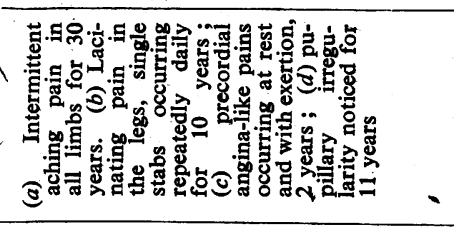 \\
\hline$\frac{\ddagger}{4}$ & $\begin{array}{l}7 \\
4\end{array}$ & $\frac{n}{n}$ \\
\hline $\bar{z}$ & \pm & $\underline{m}$ \\
\hline
\end{tabular}


Pupillary Abnormalities. - In eight cases there was evidence of unilateral pupillary disorder only, in seven cases bilateral changes were found-a total of twenty-two affected pupils. The proportion of bilateral cases is much higher than in other recorded series.

Size and Shape.-All the patients were examined in dull diffuse daylight and the pupillary size was noted after fixation on a distant object, allowing sufficient time for the pupil to reach a constant size. Measurement is sometimes difficult where pronounced irregularity exists-in general the diameter of the circle which most closely approximated in area to that of the pupil was chosen. Among the twenty-two affected eyes the pupil diameter varied from $2 \mathrm{~mm}$. (Case 15) to $9 \mathrm{~mm}$. (Case 12). In the eight unilateral cases the affected pupil was larger than the normal one in seven and smaller in one case. In the seven bilateral cases a diameter of $3.5 \mathrm{~mm}$. or less was seen in five eyes, this being less than the minimum normal diameter observed under these conditions of illumination. It is apparent, therefore, that a tonic pupil may be of any size, even miotic, although it is more commonly larger than a normal one in daylight.

The shape of the pupil has received little attention, though it is probably of considerable importance in considering the site of the lesion. In all cases it was irregular; some pupils were only slightly deformed, others markedly so. Sectors of the margin may be straight or angulated; others appear to be retracted towards the attached border of the iris, giving an ovoid shape to the pupil. In some eyes the pupils appeared to be made up of two halves-both semicircular but of different sizes. These irregularities of the iris margin are usually retained when the pupil contracts. Moreover, the pupil may be eccentrically placed in the iris; this was noted in eight of the twenty-two affected eyes. Partly this is due to irregularity of the pupil, but it may be seen when the latter is not very pronounced.

Light Reaction.-With two exceptions (Cases 14 and 15), contraction of the pupil to torch light was lost in all cases. These exceptions concerned, first, one eye of a bilateral disorder in which the pupil was irregular and showed a slightly delayed relaxation after convergence-evidently a very early change-and, secondly, one eye of another bilateral case in which exposure to torch light provoked slight but otherwise normal pupillary contraction. This pupil contracted and relaxed slowly with convergence.

It is well known that the tonic pupil may dilate in the dark and then slowly contract on re-exposure to daylight. The existence of this latent light reaction can be more easily demonstrated exposing the pupil, in a dark room, to intense illumination. A 100-watt electric lamp at distance of 6 to 8 inches from the eyes was usea for this purpose. This resulted in a definite tonie reaction, that is, a slow contraction and relaxatiom in twelve eyes and a doubtful one in two other eyes. In a single instance the response was normally brisk and relaxation was not slow, al: though there was no contraction to torch ligh In four eyes there was no response to such ag intense stimulus, nor did these pupils dilate in the dark; light rigidity in these cases was complete

When the duration of the reaction was time it was found that contraction and relaxation were usually affected unequally and that either movement might be slower than the other. More commonly relaxation was the slower movement but in four eyes it occurred at greater speed tham the preceding contraction. This latter finding was unexpected, as it is commonly asserted that one the essential features of the tonic reaction is that relaxation is slower than contraction. In no coses was this tonic light reflex excessive in amouñt in unilateral cases the final size of the pupil af always larger than in the normal eye.

There is therefore no typical reaction of the tonic pupil to light. In the early stages of the disorder whef other pupillary reactions are tonic it may stillobe normally brisk. On the other hand it mays be completely unreactive to light or shade. Betwem these extremes most cases will show evidence $+0 \hat{b}$ " tonicity" but only when intense illumination is used. With a weak stimulus (torch light) n\& contraction is usually visible. It may be noted that in no case was the light response the onlog pupillary movement to be affected.

The Convergence Reaction.-A tonic pupillar@ reaction on convergence of the eyes was found in all except one case. This patient (Case 6) had 悉 dilated pupil, fixed to light and convergence, but: showed a slowness of accommodation. With this exception each of the twenty-two eyes showe $\Phi$ what has usually been regarded as a typica電 response-a slow contraction and an equal of usually greater sluggishness of relaxation. It is difficult to know what should be regarded as the normal maximal times for these movements. Case 14, where a relaxation of $1 \mathrm{~mm}$. took 4 secondsp and Case 13, where a relaxation of $1.5 \mathrm{~mm}$. took. 5 seconds, have been regarded as showing slight but definite evidence of abnormality. In each of these cases the opposite eye showed a more pros nounced reaction. Where movement is very sloves 
it is extremely difficult to time the end point in either direction with precision, and frequently several attempts are necessary to obtain even an approximate result. Within these limitations the range of values has been : for contraction normal (2) to 90 seconds ; for relaxation 4 to 135 seconds (all measurements by stop watch). Only exceptionally did contraction take longer than 20 seconds or relaxation more than 40 .

Adie claimed that delay in addition to slowness of movement was the essential feature of the tonic reaction. Again, accurate assessment is difficult and probably necessitates the use of a slit lamp, which was not used in this series ; but the impression gained has been that such delay is rather unusual and that when it occurs it is more frequently seen at the beginning of contraction than at the commencement of relaxation. It is certainly not always seen.

One other feature of the convergence reaction has often been stressed, namely, the excessive contraction which may, so it is said, continue even after convergence has been relaxed. Miosis, by which is meant a pupil of $2.5 \mathrm{~mm}$. diameter or less, was produced with convergence in eight affected pupils (Cases 3, 9, 10, 13, 14, and 15). However, the resting diameters of the pupils in these cases were never greater than $4 \mathrm{~mm}$. and, since in normal eyes convergence may result in a contraction of one third of the resting diameter (Kestenbaum, 1947), this miosis may fairly be regarded as not very excessive. In only one of the eight unilateral cases (Case 3) was the affected pupil smaller than the normal one at the end of convergence. Continuation of contraction after cessation of convergence was never seen, and it seems doubtful whether this ever occurs.

If we exclude phases of the disorder in which the pupil is dilated and fixed it would seem from this series that the essential feature of the tonic pupil is its failure to dilate promptly when the eye relaxes from a convergence movement. This may be the only evidence of "tonicity" of the pupil and it clearly is the main justification for the term, because sluggishness of contraction may be, in fact, purely a paretic dysfunction. Just as it is probably the earliest tonic feature, so it is usually the most pronounced one in a temporal sense, being almost always of longer duration than contraction. The two movements may sometimes be equally slow, but relaxation is never faster than contraction.

Accommodation.-Defective accommodation and ipsilateral frontal headaches are the only ocular symptoms produced by the condition. They occur in a few patients. In these cases the onset is fairly abrupt, the patient noticing that he cannot see objects clearly for a brief period immediately he looks at them. More frequently near objects only are affected in this way; less commonly distant objects are transiently blurred. Power of accommodation may also be weakened as well as delayed and the near point of the eye may recede.

These symptoms are associated with an enlargement of the affected pupil and they may disappear after a period of weeks or months although the latter remains. On the other hand, defects of accommodation which have never been appreciated by the patient may be found on routine testing.

Accommodation was tested by first measuring the near point of the eye. Then a Jaeger test type which could be read comfortably at a distance greater than this (usually $\mathrm{J} 4$ to $\mathrm{J} 8$ at $30 \mathrm{~cm}$.) was held between the patient's eye and a distant object (a chimney pot about seventy-five yards away) seen through the window of the room. He was asked to look from one to the other as the test type was removed or replaced and to say immediately when the near or distant object became sharply focused. Any delay was timed by a stop watch. Normally there is no measurable delay. In all except six eyes some delay was found by this method. In the sixteen eyes in which such tonic accommodation was present the delay was found on looking only from the far to the near object in thirteen cases ; only from the near to the far object once ; and in both directions twice. These results are unusual in two respects ; first, in the matter of their frequency, for disturbances of accommodation are generally assumed to be relatively uncommon in this condition; and, secondly in the fact that delay in focusing was most commonly seen only when a near object was being looked at, that is, during active contraction of the ciliary muscle. Slow relaxation of this muscle was rare, a finding at variance with what is commonly described. Delay in accommodation was, therefore, usually the result of a feebleness of action of the ciliary muscle. In spite of this, however, paresis of accommodation, as judged by a near point greater than $20 \mathrm{~cm}$., was seen in only five eyes, Cases 8 and 10 being most definite. This slowness of accommodation was never as great as the corresponding slowness of the sphincter muscle during convergence. It varied from 1 to 6 seconds.

In contrast, therefore, to the convergence reaction, true tonicity, that is, delayed relaxation, of accommodation is less frequently seen than simple sluggishness of ciliary contraction. The latter is analogous to the few instances in which contraction of the pupil to light was more delayed than subsequent relaxation. 
Adie stated that isolated tonic accommodation was unknown. This is confirmed in the present series and no such cases have been found in the literature. In all the sixteen eyes mentioned above there was a tonic reaction on convergence and an absent or tonic light reflex, with the exception of Case 6 in which the pupil was fixed both to light and on convergence. In this patient accommodation for near vision was delayed 5 seconds and there was a paresis of accommodation (near point $29 \mathrm{~cm}$.).

In brief, therefore, disturbances of accommodation are common, though they are often unnoticed by the patient, and a slowness of contraction of the ciliary muscle is found more frequently than a slowness of relaxation. These changes are never seen in isolation, and their only practical value is in the diagnosis of the type of tonic pupil which presents as a dilated and fixed pupil.

Other Pupillary Reactions.-When the eyes are tightly closed the pupils may contract in normal persons. Usually, however, they dilate, owing to the removal of the light stimulus. Whether the former reaction occurs probably depends on whether the eyes converge behind the closed lids. Similarly tonic pupils may contract when the eyes are closed. This, as in the normal case, is relatively uncommon, having been seen only on three occasions in the series. In bilateral cases it may be more marked in one eye than another. Once contracted the pupil shows the same delay in relaxation as after voluntary convergence. In most cases, however, the tonic pupil remains unchanged in size during firm lid closure.

Both Holmes and Adie mention that the pupil may contract during crying. This was seen on one occasion in Case 12, a child aged 12 who became alarmed and tearful when told that drops were to be put in her eyes. Both pupils, from being widely dilated $(9 \mathrm{~mm}$.), soon contracted down to $7 \mathrm{~mm}$. and slowly dilated after her sobbing had ceased. Unfortunately this was not timed. Presumably this pupillary reaction is part of a more widespread parasympathetic discharge which occurs in crying.

Reaction of the Pupil to Drugs.-The tonic pupil reacts normally to the conjunctival instillation of homatropine and eserine. Alajouanine and Morax (1938) go further and state that in every case there is a " precocious" reaction, dilatation or contraction occurring more rapidly in the affected eye than in the normal eye. Lowenstein and Friedman (1942), moreover, found that at a certain stage of the contraction of the pupil to eserine the light reflex returned. Neither of these observations has been confirmed. In two bilateral tonic pupils (Cases 11 and 15) homatropine did not produce fư dilatation in one eye. In all other cases tested normal results were obtained.

Scheie (1940) reported a series of six patients in all of whom contraction of tonic pupils occurreg with a $2 \frac{1}{2}$ per cent. solution of acetyl $B$ meth choline ("Mecholyl"), a concentration too weak. to affect a normal pupil. His results are confirme by Walsh (1947), who considers the test of great diagnostic value. A $2 \frac{1}{2}$ per cent. solution $\overrightarrow{\text { of }}$ "Amechol" (Savory and Moore) was used on af patients-2 drops from an unstandardized dropper being placed in each eye. A contraction of $1 \mathrm{mn}$. after 30 minutes was seen in four eyes ; of $1.5 \mathrm{~mm}$. in 2 ; of $2 \mathrm{~mm}$. in 1 eye ; of $2.5 \mathrm{~mm}$. in 1 , and of $5.7 \mathrm{~mm}$. in 2 . No response was found in twelve eyes? The response is therefore variable, but the test $\overrightarrow{\mathrm{s}}$ worth applying for a positive result is of great help when the diagnosis is in some doubt.

When contraction occurred with this drug there was no change either in the light reflex or in the pupillary response to convergence, but in onis patient (Case 12) the delay of accommodation wass abolished and the near point of the eyes redugds and in another (Case 6) the delay in accommodati was reduced.

Associated Loss of Tendon Reflexes.-Of fifteen patients studied, twelve had absence of ons or more reflexes, one had a sluggish right are jerk, and in only two (Cases 2 and 8 ) were the reflexes normally brisk.

Associated Symptoms.-Apart from blurring of vision and ipsilateral headaches, the Holmes-Adie syndrome is generally considered to be asymptoms atic. Holmes (1931), it is true, mentioned the occurrence of mild pains and paræsthesiæ in the limbs at the time of onset of the pupillary disturbo ances, but Adie did not refer to them. Frenc $\vec{B}$ writers, however, have frequently stressed the existence of obscure pains in many patients wit this syndrome, pains which can be related neither? to the pupillary or the reflex changes. Achin pains, muscle stiffness, cramps, and even shar stabbing pains of a lightning type have bee described in the limbs. Severe localized or generaf. ized headache of both migrainous and non-specifio type and unrelated to the pupillary abnormality anginal chest pains, and pains in the throat and neck have also been reported (Barré and Klein 1934 ; Lhermitte, 1937 ; Alajouanine and Moras. 1938 ; Sigwald, 1941).

Careful inquiry in this group of patients revealed that such symptoms are, in fact, not uncommonls experienced (Cases 6, 7, 9, 14, and 15). The 
nature is quite obscure, and they may sometimes add yet another difficulty to the differentiation of the condition from neurosyphilis.

\section{Diagnosis}

From the experience of these cases it would seem that there are two types of tonic pupil.

The "Fixed" Type.-This is the less common variety. Here the disturbance is unilateral and the affected pupil is larger than normal, irregular in shape, and totally unresponsive to light or convergence. The only means of distinguishing it clinically from a complete ophthalmoplegia interna is by testing the accommodative mechanism. In the tonic pupil this is usually not paralysed completely and may show slowness of contraction or, less often, of relaxation. Such a pupil may contract under acetyl $B$ methyl choline and this may help in differentiation. This type may change after a varying period into the second type.

The "Ordinary" Type.-Here the disturbance may be unilateral or bilateral. The pupil may be of any size ; it is irregular in shape, and often eccentrically placed in the iris. The essential feature is a slowness of dilatation after convergence. This is always present, and may be the only evidence of abnormal pupillary movement in the early stages. Usually, however, contraction on convergence is also slow and is sometimes both delayed in onset and excessive in amount. In this type the light reflex may be normal in the early stages, but later is either completely absent or may show a slowness of contraction and relaxation when intense illumination is applied. Tonic accommodation may or may not be present. The various combinations of reactions which may, therefore, occur-are numerous, so much so that Adie's classification into "typical" and "atypical" phases seems unjustified. The only typical features in the sense that they are always seen in this second type are $(a)$ the irregularity of the pupil, and $(b)$ the slowness of relaxation after convergence.

Comparing these changes with what may be seen in the pupil in neurosyphilis there are several obvious points of similarity. In both the pupil may be irregular, it may be of any size, and it may show no response to light. Contraction of the pupil on convergence may be sluggish but when this happens in neurosyphilis the subsequent dilatation is normal, whereas in the tonic pupil it is always more delayed. This is the most important distinguishing feature and the surest way by which the two conditions may be differentiated by simple clinical examination.

In the phase of the fixed dilated pupil differentia- tion is more difficult and depends on the recognition of tonic accommodation. Should this be absent, then full laboratory investigation of blood and cerebrospinal fluid may be required.

\section{Pathology of the Tonic Pupil}

The tonic pupil in Adie's view was " a benign disorder sui generis" and since his time, although no pathological studies have ever been made and no cause has ever been advanced to account for it, it has been regarded in this country as an innocent condition with probably a uniform ætiology. A perusal of the literature, however, suggests that such a view is not altogether supported by experience.

Before and since Adie's publication cases of tonic pupil have been recorded in association with other diseases, for example, trauma (Axenfeld, 1906 ; Oloff, 1914 ; Roemheld, 1921), diabetes (Nonne, 1902), and malignant basal intracranial tumour (Garcin and Kipfer, 1936). In the present series of cases there is one (Case 8) where the tonic pupil was a direct and isolated sequel to a head injury. Tonic pupil has also been described as a familial disturbance (Dressler and Wagner, 1937 ; McKinney and Frocht, 1940), and Lowenstein and Friedman (1942) report slight pupillary abnormalities in the mothers of some of their patients.

Discussion has principally centred on whether a tonic pupil may be caused by neurosyphilis. Such a possibility has never been accepted in this country, notwithstanding the difficulties that may arise in distinguishing the two conditions. In France, however, several cases have been described in which cerebrospinal fluid changes and a positive Wassermann reaction in the blood have been found. These are enumerated-in the paper of Alajouanine and Morax (1938), the most comprehensive one on the subject yet written. These authors record eight personal cases of tonic pupil, of which they consider one was certainly due to syphilis and three others probably so. They stress the point that in their own and other cases the infection has been of very long standing and frequently hereditary in origin. Though the total number of such cases is small, and coincidence, therefore, cannot be ruled out, it seems justifiable to entertain the possibility that occasionally syphilis may be the cause of the tonic pupil. As a morbid physiological entity it would indeed be surprising if it had a single pathology, and if this be admitted there seems no reason why syphilis should not occasionally be the cause.

In practice, however, the vast majority of cases are of unknown ætiology, and adequate observation over long periods of time has shown that the disorder is not the result of any progressive neuro- 
logical diseàse. With the one exception mentioned, no cause was found for the disorder in any of the present cases.

\section{The Anatomical Site of the Lesion}

Several suggestions have been made about the possible site of the lesion causing a tonic pupil. The absence of any post mortem confirmation renders discussion purely speculative, but in spite of this the clinical features of the condition, when critically considered, limit the possibilities to a greater extent than theories have hitherto suggested. Five sites have been postulated: (1) the supranuclear oculomotor pathways (Lowenstein and Friedman, 1942), (2) the hypothalamus (Kennedy and others, 1938), (3) the third nerve nucleus (Adie, 1932 ; Behr, 1921), (4) the ciliary ganglion and/or the ciliary nerves (Magitot, 1911), and (5) the sphincter muscle (Saenger, 1902).

Of these hypotheses, (1) and (2) may be dismissed at once for the absence of a light response in a unilateral tonic pupil with the retention of a consensual reaction in the normal pupil places the lesion on the efferent limb of the light reflex arc. Saenger's suggestion that the condition is a disorder of the sphincter muscle analogous to the myotonia of Thomson's disease may likewise be eliminated. The not infrequent absolute rigidity of the pupil to light, and less often to convergence, together with its normal contraction when stimulated directly by pilocarpine, clearly indicate that the lesion is in the nervous pathways controlling pupil movement.

It seems most likely, therefore, that the lesion affects either the vegetative portion of the oculomotor nucleus or some part of the peripheral path of its emerging fibres. At this point argument is hampered by a lack of precise anatomical knowledge concerning the origin and course of fibres which control the pupillary reflexes. It is generally agreed that the Edinger-Westphal nucleus is the origin of fibres which subserve the light reflex. These run to the sphincter muscle via the ciliary ganglion and the short ciliary nerves. They are usually described as being unilateral in distribution. Langworthy and Ortega (1943), however, state that each nucleus supplies fibres to both oculomotor nerves. If this is so, then unilateral disorders of the light reflex can only arise from peripherally situated lesions. If not, however, it is conceivable that the changes seen in the tonic pupil may have a central cause.

Greater obscurity surrounds the pathway of fibres which govern reflex pupillary contraction on convergence of the eyes. Its origin is depicted sometimes as the caudal end of the EdingerWestphal nucleus, sometimes as the median nucleus of Perlia whence fibres run to both oculomotor nerves. Their peripheral pathway is unknown, but they probably do not pass through the ciliary ganglion. Foerster and others (1936) have shown that removal of this structure in apes abolishes the light reflex but not pupillary contraction on con vergence. In man, Nathan and Turner (1942) have similarly reported isolated light rigidity of the pupil following head injuries in which it seemes. reasonably certain that the traumatic lesions were peripherally situated. They suggest that conver: gence fibres may relay in the episcleral ganglia of Axenfeld which lie in the scleral canals in close proximity to the short ciliary nerves.

In the midst of this anatomical uncertainty, any attempt to localize further the site of disturbanco of the tonic pupil must remain hypothetical. There seem to be valid reasons, nevertheless, for rejecting Adie's theory of a central nuclear disturbance. The term tonic pupil conjures up an idea of pupillary rigidity dependent on excessive tone preventing sphincter' movement. Adie (1932) for instance speaks of a pupil "so stiff that at the time of examination no reaction to light or on convergence is obtained " and, again, visualized stimuli " store $\omega$ in excess and slowly liberated" from the cellsolis the oculomotor nucleus so producing slowness $\overrightarrow{0}$ op contraction and relaxation. These two ideas ofre mutually exclusive since the first would depend $\delta^{-1}$ an excessive and continuous sympathetic tome whilst the second implies a continuous parasympa thetic discharge.

Moreover, since, as we have seen, a tonic p审 may be persistently larger or smaller than normate and is always irregular, it is difficult to conceive how these various changes may result from nuclear lesion.

We are therefore left with the hypothesis that the lesion lies in the peripheral oculomotor pathwas viz. in the ciliary ganglion or the short ciliary nerves-a suggestion first made by Magitot (1911 $\bar{\Phi}$ and lately revived by Scheie (1940) and Leathart (1942). There is much to recommend this idea though in its simplest form it fails to explain a the changes seen. Scheie suggests that there is a incomplete interruption of transmission in the ganglion or nerves which accounts for the sluggish ness or absence of pupillary contraction. He further suggests that this partial interruption of conduction results in a slow liberation of acetyk choline at the myoneural junction which diffuses through the sphincter muscle and so hinders its relaxation. If this were so it might be expected. that pupillary contraction would start in isolated segments of the iris and spread slowly to neighboursing ones. In fact no such movement occurs. Whes contraction occurs the iris widens more or less 
uniformly so that the irregularity of its margin remains unchanged. Nevertheless the implication of Scheie's suggestion, namely that there are probably two fundamentally distinct changes, one in the peripheral nerve the other at the myoneural junction, seems a new and fruitful approach to the problem.

We have seen that sometimes light rigidity of the tonic pupil is complete and that there may be no movement of the pupil with ocular convergence, no matter how intense the stimulus may be. There is, in fact, in such cases a paralysis of the sphincter muscle and the pupil is dilated. This can only be the result of an interruption of fibre conduction. In less severe cases the pupil contracts only under intense illumination and does so slowly. This suggests a partial interruption of conduction in the efferent fibres, and we may suppose that usually this affects the short ciliary nerves to a greater extent than the still hypothetical convergence fibres, - for in most cases convergence results in pupillary movement when the light reflex is completely or almost completely absent. The irregularity of the pupil may be explained by supposing that these changes do not affect the ciliary nerves uniformly.

Sluggishness of contraction is, therefore, merely an indication of a partial interruption of conduction in the efferent fibre. But delayed conduction will not explain slowness of relaxation. Here we must assume a functional disturbance at the myoneural junction ; that, just as there is a slow liberation of acetylcholine, so its destruction by cholinesterase is delayed. The contraction of a tonic pupil produced by concentrations of acetyl $B$ methyl choline which are too weak to affect normal pupils lends support to this suggestion, for in normal eyes this substance is presumably destroyed by the cholinesterase present.

It is, therefore, possible to construct a plausible working hypothesis concerning the underlying physiopathological disorder which results in a tonic pupil. There is, first, a disturbance of conduction in pupillomotor fibres, and secondly an alteration in the chemical changes resulting from such stimuli at the myoneural junction. Possibly the latter is a sequel of the former. The conduction defect occurs in the short ciliary nerves conveying the light reflex fibres and, to a greater or lesser extent, in the still unknown convergence reflex fibres. As a result of this the pupil may become completely immobile. More often its response to light is impaired and sluggish so that it may only contract slowly on exposure to a strong source of illumination, whilst its contraction on convergence, although slow, is more readily demonstrable. At the same time a delay in the destruction of acetyl- choline at the myoneural junction prevents normal relaxation and results in slowness of dilatation after the pupil contracts. This is best seen with the convergence movement which is a stronger stimulus to pupillary movement. Such a biochemical change may fluctuate and be responsible for the occasional variable size of the tonic pupil from day to day.

The site of the lesion producing a tonic pupil is therefore, on this view, at the efferent end of the pupillary reflex pathway. Circumstantial evidence supporting this is found in the occasional occurrence of a tonic pupil after orbital injuries. Such cases have been recorded by Axenfeld (1906) and Ohm (1907).

If this hypothesis is correct it follows that the tonic pupil should always be larger than normal. In most cases this is so, but occasionally it may be smaller and sometimes even miotic. In such cases there may be, in addition, a paresis of the dilator mechanism, and it may be that the same process that attacks the parasympathetic fibre spreads to adjacent sympathetic nerve endings. The very occasional occurrence of a partial ptosis in association with a tonic pupil (Alajouanine and Morax, 1938 ; Moore, 1931) supports such a view.

The very frequent association of the tonic pupil with absent tendon reflexes raises the suspicion that the two phenomena have a common pathological cause and a similar underlying anatomical or biochemical defect. Tendon areflexia in such cases is unaccompanied by any of the objective motor or sensory changes, which in other diseases help to determine the site of the lesion causing loss of reflexes. This isolation of the absent reflex, however, may possibly be a point in favour of regarding it as being due to a peripheral defect. Whether this lies on the sensory side of the reflex arc, whether, for example, there is some change in the strétch receptors, or on the motor side, as for instance in the motor fibre or at the myoneural junction is, however, quite unknown. Arguing by analogy from the probable site of the lesion causing the tonic pupil, it seems perhaps more likely that the lesion is in the motor pathway, but this conclusion is purely a speculative one for as yet we possess no. knowledge, either clinical or pathological, to help in the elucidation of this problem.

\section{Summary}

1. Fifteen patients with tonic pupils have been studied. The variability from case to case of the abnormal pupillary reflexes is stressed; no single combination can be regarded as typical.

2. Two types of tonic pupil may be distinguished (a) the fixed type, and (b) the ordinary type of tonic 
pupil. The only features common to all examples of this latter variety are (1) the irregularity of shape or position of the pupil and (2) the slowness of pupillary dilatation after convergence.

3. Defects in accommodation are common and often pass unrecognized.

4. The possible anatomical site of the lesion causing the tonic pupil is discussed.

I wish to thank Dr. F. R. Ferguson for his permission to publish details of patients under his care at the Manchester Royal Infirmary and for his advice in the preparation of this paper.

\section{REFERENCES}

Adie, W. J. (1931). Brit. med. J., 1, 928. (1932). Brain, 55, 98 .

Alajouanine, Th., and Morax, P. V. (1938). Ann. Oculist, Paris, 175, 205.

Axenfeld, T. (1906). Dtsch. med. Wisch., 32, 663.

Barré, J. A., and Klein, M. (1934). Rev. Neurol., 1, 590.

Behr, C. (1921). Klin. Monatsb. Augenheilk, 66, 770.

Bramwell, E. (1936). Trans. Edinb. Med. Chir. Soc., 115, 83.

Collier, J. (1933). In "A Textbook of the Practice of Medicine," edited by F. W. Price, 4th Edition, Oxford University Press, London.

Dressler, M., and Wagner, H. (1937). Schweiz Arch. Neurol. Psychiat., 39, 246, and 40, 50.

Foerster, O., Gagel, O., and Mahoney, W. (1936). Verh. Disch. Ges. Inn. Med., 48, 386.

Ford, F. R., Walsh, F. B., and King, A. (1941). Bull. Johns Hopk. Hosp., 68, 309.

Garcin, R., and Kipfer, M. (1936). Rev. Neurol., 65, 128.
Holmes, G. M. (1931). Trans. Ophthal. Soc. U.K., 51, 209.

Kennedy, F., Wortis, H., Reichard, J. D., and Fair, B. B. (1938). Arch. Ophthal., Chicago, 19, 68.

Kestenbaum, A. (1947). "Clinical Methods of NeuroOphthalmological Examination." Heinemann, Lon don.

Langworthy, O. R., and Ortega, L. (1943). Medicine, (D) 22, 287.

Leathart, P. W. (1942). Brit. J. Ophthal., 26, 60.

Lhermitte, J. (1937). Rev. Neurol., 67, 210.

- and Eschbach, H. (1937). Ibid., 68, 713.

Lowenstein, O., and Friedman, E. D. (1942). Arch Ophthal., Chicago, 28, 1042.

Magitot, A. (1911). Ann. Oculist, Paris, 144, 258.

Markus, C. (1906). Trans. Ophthal. Soc. U.K., 26, 50.

McKinney, J. M., and Frocht, M. (1940). Amer. J. med. Sci., 199, 546.

Moore, R. F. (1924). Trans. Ophthal. Soc. U.K., 44, 38. (1931). Ibid., 51, 203.

Morgan, O. G., and Symonds, C. P. (1927). Guy's sis Hosp. Rep., 77, 13:

L, (1931). Proc. R. Soc. Med., 24, 867.

Nathan, P. W., and Turner, J. W. A. (1942). Brain, 65, 343.

Nonne, M. (1902). Neurol. Zbl., 21, 1000.

Ohm, J. (1907). Zbl. prak. Augen., 31, 193.

Oloff, H. (1914). Klin. Monatsb. Augenheilk, 18, 493.

Roemheld, L. (1921). Neurol. Zbl., 40, 100.

Saenger, A. (1902). Ibid., 21, 837 and 1137.

Scheie, H. G. (1940). Arch. Ophthal. Chicago, 24, 20

Sigwald, M. J. (1941). Rev. Neurol., 73, 146.

Strasburger, J. (1902). Neurol Zbl., 21,738 and 1052 ब

Walsh, F. B. (1947). " Clinical Neuro-Ophthalmology, Williams and Wilkins Co., Baltimore.

Ware; James (1818). "Observations on the treatment of the Epiphora or Watery Eye ; and on the Fistudic Lacrymalis." Edited by his son Martin Wafe. T. and G. Underwood, Fleet Street, London.

Weber, F. P. (1923). Proc. R. Soc. Med., 16, (Seç Dis. Child), 16, 68. 